\title{
A cultura de belezas americanas: gestão de pessoas, discurso e sujeito
}

The culture of American beauties: managing people, discourse, and subject

\author{
Fabio Bittencourt Meira ${ }^{1}$ \\ Mônica Birchler Vanzella Meira ${ }^{2}$
}

\section{Resumo}

O discurso organizacional parece incapaz de induzir comportamentos alinhados com as exigências e necessidades da empresa. A literatura sobre gestão de pessoas aponta essa dissociação entre discurso e prática como um paradoxo. Este artigo propõe ir além, ao considerar que ele é, na verdade, signo de uma contradição constitutiva do campo a partir da qual as ações gerenciais são produzidas. A não coincidência entre discurso e prática é a regra que propicia a regeneração e reiteração incessante do que é comunicado. Técnicas renovadas de treinamento mostram que a integração dos indivíduos é vista como um problema de aprendizagem, dependente do ensino de modos de sentir e perceber suas sensações e experiências, o que vai muito além da fronteira do discurso, apontando outros limites e antagonistas. Espera-se que os indivíduos sejam sujeitos de sua própria sujeição. Nessa perspectiva, a operação e o problema da gestão de pessoas residem na necessidade de produzir simultaneamente a completa sujeição e o sujeito pleno. Os referenciais teóricos do discurso organizacional e da teoria linguística fundamentam a crítica às práticas inovadoras de gestão de pessoas. Um dos personagens do filme Beleza americana ajuda a reordenar a reflexão anterior, propiciando a retomada do problema segundo a nova chave, com a passagem do discurso ao sujeito.

Palavras-chave: Gestão de pessoas. Discurso organizacional. Sujeito. Ideologia. Análise fílmica.

\begin{abstract}
Organizational discourse seems unable to incite behaviors in line with the company's requirements and needs. The literature on people management points out this dissociation between discourse and practice as a paradox. This article proposes to go further, by regarding it, actually, as the sign of a constitutive contradiction of the field in which managerial actions are produced. The mismatch between discourse and practice is the rule that enables the ceaseless renewal and reiteration of what is communicated. Renewed training techniques show that the integration of individuals is seen as a learning issue, which depends on teaching ways of feeling and noticing their sensations and experiences, something which goes far beyond the discourse boundary, pointing out other thresholds and antagonists. It is expected that the individuals are subjects of their own subjection. From this perspective, operation and the issue of people management lie on the need to simultaneously produce complete subjection and a full individual. The theoretical frameworks of organizational discourse and linguistic theory ground the criticism to innovative practices in people management. A
\end{abstract}

Artigo submetido em 19 de julho de 2013 e aceito para publicação em 10 de janeiro de 2014.

1 Doutor em Administração pela Fundação Getulio Vargas / Escola de Administração de Empresas de São Paulo; Professor Adjunto da Escola de Administração da Universidade Federal do Rio Grande do Sul. Endereço: Rua Washington Luiz, 855, Centro Histórico, CEP 90010-460, Porto Alegre - RS, Brasil. E-mail: fabio.meira@ufrgs.br

2 Doutora em Ciências Sociais (Antropologia), Bacharel e Mestre em Administração de Empresas pela Pontifícia Universidade Católica de São Paulo/PUC/SP; Professora do Centro Universitário Univates (RS); Pesquisadora do Núcleo de Estudos da Complexidade - Complexus (PUC/SP). Endereço: Rua General Oliveira Freitas, 76, Santa Tereza, CEP 90810-210, Porto Alegre - RS, Brasil, E-mail: mmeira@yahoo.com 
character from the movie American Beauty helps rearranging the previous reflection, enabling us to resume the problem according to the new key, moving from the discourse to the subject.

Keywords: People management. Organizational discourse. Subject. Ideology. Film analysis.

\section{Introdução}

Paulo Storani é ex-capitão do Batalhão de Operações Especiais (Bope) e consultor. Seu trabalho consiste em transpor técnicas da corporação para as empresas. No treinamento experiencial de uma grande seguradora, as práticas policiais são aplicadas com poucos ajustes (PRADO, 2008). Uma das práticas é descrita assim: “funcionários cumprem 'missão' dentro d'água". O dialeto policial é também mimetizado: o "[...] jargão 'missão dada é missão cumprida' ganha a conotação de 'meta dada é meta cumprida'. 'Vá e vença' vira 'vá e venda"". Os funcionários, às vezes constrangidos, balançam a cabeça em sinal de concordância. No grand finale do treinamento, liderados pelo consultor, todos gritam: 'Eu sou caveira!' (PRADO, 2008).

Na mesma sintonia, a empresa Meta Treinamento Corporativo vende-se pelas cenas que animam sua página eletrônica. A imagem de um jovem arrastando-se num poço de lama é acompanhada dos dizeres: "é preciso mergulhar de cabeça nos ideais da empresa" (META, 2013). Um homem equilibra-se numa ponte flutuante e o subtítulo afirma que "a empresa que oferece treinamento jamais afunda" (META, 2013). Rapazes enlameados de braços erguidos explicam a legenda: "transforme sua equipe num time de verdade" (META, 2013). A consultoria diz tratar-se do treinamento experiencial ao ar livre (Teal), "uma ferramenta insuperável para a formação de equipes altamente entrosadas, capazes de planejar, tomar decisão e agir rapidamente, quando a velocidade da ação é a chave do sucesso" (META, 2013).

Todas essas práticas têm como referência a educação experiencial iniciada durante a II Guerra Mundial, para treinar sobreviventes da marinha mercante inglesa a utilizar barcos salva-vidas depois de ataques navais alemães. O objetivo era lapidar o caráter individual por meio de desafios no meio natural. "[O] ambiente ao ar livre tem longa história por prover espaços especiais para que o indivíduo aprenda, de modo profundo, sobre si mesmo e sobre sua interação social com os outros." (REIS, 2010, p. 36). Treinamentos comportamentais experienciais começam a ser utilizados pelas corporações no Brasil, a partir do início dos anos 1990. A aplicação de esportes e atividades ao ar livre a grupos de empregados objetiva desenvolver habilidades e competência. Geralmente, visa "reforçar a missão da empresa ou [...] modificar comportamentos inadequados à realidade corporativa" (KILIMNIK e REIS, 2010, p. 20).

O processo se inicia com a experiência, seguindo-se a reflexão, discussão, análise e avaliação da experiência. O pressuposto é que raramente aprendemos com a experiência, a não ser quando a avaliamos, atribuindo-lhe nosso próprio significado em termos de nossas metas, ambições e expectativas. (BANK,1994 apud BURKE e COLLINS, 2004, p. 679).

É preciso vivenciar comportamentos adequados às necessidades corporativas para depois falar e refletir sobre eles. Tudo se passa como se o discurso precisasse assumir-se como ação, além de si mesmo, ao ser enunciado: é imperativo agir. O objetivo mais ambicioso é a aprendizagem, definida como "uma modificação sistemática do comportamento, por efeito da prática ou experiência, com um sentido de progressiva adaptação [...]" (CAMPOS, 1987 apud REIS, 2010, p. 40). Toda assimetria deve ser corrigida pelo esforço do próprio empregado. Por isso, os mecanismos de ajuste comportamental devem ser acionados ininterruptamente.

Esse circuito evidencia o que, para alguns, define um paradoxo, isto é, a "existência simultânea de duas realidades contraditórias: o discurso da organização e a sua prática efetiva em relação a um mesmo objeto" (VASCONCELOS, MASCARENHAS e VASCONCELOS, 2004, p. 4). As organizações adotam retórica inovadora, mas não conseguem transformá-la em padrões comportamentais efetivos. Modelos pregados 
como ideais e práticas em gestão de pessoas produzem percepções contraditórias nos empregados (VASCONCELOS, 2004). A fala oficial induz expectativas que não se realizam, provocando reações defensivas que aumentam o nível de frustração, tensão e estresse. Quando aderem aos ideais de qualificação e aprendizagem do discurso oficial, os indivíduos percebem a desconexão com seu trabalho concreto. Esta contradição é entendida assim, porque impede a realização dos objetivos veiculados ao não abrir espaço para a construção das competências necessárias para tal, o que realimenta o circuito vicioso (VASCONCELOS, MASCARENHAS e VASCONCELOS, 2004).

Este artigo propõe ir um pouco além disso, ao considerar que o paradoxo é, na verdade, signo de uma contradição constitutiva do campo, a partir da qual as ações gerenciais são produzidas. A não coincidência entre discurso e prática parece ser a regra que autoriza a renovação e reiteração constante do que é comunicado. Dessa perspectiva, a operação e o problema da gestão de pessoas residem na necessidade de produzir simultaneamente a completa sujeição e o sujeito pleno. O esforço em integrar os indivíduos a partir da educação de seus modos de sentir e perceber suas sensações e experiências mostra mais do que a fronteira do discurso. Revela outros limites e antagonistas.

O desenvolvimento do texto combina a análise de inovações e modismos gerenciais com o filme Beleza americana. São quatro seções além desta introdução e das considerações finais. De início, é apresentado o referencial teórico do discurso organizacional e da teoria linguística para, em seguida, articulá-los com as práticas de gestão de pessoas. O filme reordena a reflexão na terceira parte. Finalmente, o problema é retomado em nova chave, com ênfase no sujeito.

\section{Discurso Organizacional e Modelagem Linguística do Universo}

O discurso organizacional pode ser descrito como a linguagem e o suporte simbólico adotado para explicar, representar, interpretar e teorizar o que se considera ser a realidade da vida organizacional (GRANT, KEENOY e OSWICK, 2001). É operação simbólica e consciente, constitutiva daquilo que Prestes Motta (1995a, p. 199) definiu como uma cultura: "um sistema de símbolos e significados compartilhados que serve como mecanismo de controle". Na organização, a cultura é o que dá suporte ao discurso, oferecendo os princípios de ordenação, classificação e categorização, sem os quais seria impossível efetivá-lo. A existência mesma das organizações está intimamente relacionada com o discurso, principal meio pelo qual seus membros criam uma realidade coerente, que faça sentido para eles (GRANT, KEENOY e OSWICK, 2001).

A organização formal não pode dispensar o trabalho sistemático de reiteração de seu discurso, para que a elaboração de uma explicação da realidade (por meio de símbolos) converta-se em referência dessa mesma realidade. Todo discurso organizacional implica um uso da língua consoante à ordenação enunciada. Só assim torna-se possível, por exemplo, denominar informal um determinado conjunto de ações empreendidas por indivíduos ou grupos na organização real do trabalho, ou escolher certas designações para reordenar fenômenos reais: colaboradores, empowerment, grupos semiautônomos etc.

Esse procedimento pode ser melhor compreendido da perspectiva da "modelagem linguística do universo" que vê a linguagem como cobertura integral da realidade: "[...]a tendência dominante [na linguística moderna] tem sido considerar a língua como organizadora da estrutura conceitual do universo e já se tornou lugar-comum afirmar que ela é o 'molde do pensamento' ou o 'instrumento de análise ou recorte da realidade" (BLIKSTEIN, 1995, p. 40). A escolha dos signos para referir os fenômenos não é, portanto, neutra em relação à possibilidade de matrizá-los. Na medida em que a língua retorna sob a forma de objetos designados, iguala-se à própria realidade.

Blikstein (1995) chama atenção para o aspecto negligenciado pela tradição linguística: o processo sociocultural perceptivo-cognitivo que antecede toda significação. Signos são precedidos por processos sociais numa práxis específica que constrói "esta" realidade, e não outra: a organização perceptiva é 
tributária da vida social. A práxis é a fronteira extralinguística a ser ultrapassada pela significação, quando designamos "isto" ou "aquilo": "sem práxis não há significação" (BLIKSTEIN, 1995, p. 54). A produção de signos é correlata à "discriminação, reconhecimento e seleção" de estímulos originados do real, e o mecanismo de diferenciação - entre figura e fundo - tem fundamento na vida social. O que é representado pela linguagem não é uma realidade qualquer e universalmente válida, mas um sistema de referentes cuja organização e ordenamento dependem das práticas daquela sociedade. Os "padrões perceptivos ou 'óculos sociais' constituem, em última análise, estereótipos de percepção" (BLIKSTEIN, 1995, p. 61). A produção de signos e significados é um processo social mediado por um conjunto de formas ou corredores semânticos, por onde fluem as linhas básicas de significação da sociedade. Traços ideológicos manifestam-se na construção dessas linhas, desenhando-se como "isotopias da cultura de uma comunidade" (BLIKSTEIN, 1995, p. 61).

Em nossa cultura, por exemplo, "em pé" ou "vertical" é traço de valor meliorativo, enquanto "deitado" ou "horizontal" teria, em princípio, um valor pejorativo; a partir de tais traços ideológicos constituem-se os corredores semânticos ou isotópicos da verticalidade meliorativa vs. horizontalidade pejorativa $[\ldots]$ esses corredores $[\ldots]$ vão balizar a percepção/cognição, criando modelos perceptivos ou "óculos sociais" [...]. (BLIKSTEIN, 1995, p. 61)

Quando um discurso é enunciado, algo deve se interpor entre realidade e linguagem. Só assim a significação é produzida. Esse algo é a práxis da sociedade. A organização como produtora de sistemas simbólicos (ENRIQUEZ, 1997a) também ordena a realidade e fabrica corredores semânticos. Ao atribuir valências ao mundo, as organizações o modelam, isto é, discriminam, reconhecem e selecionam estímulos originados do real e produzem os símbolos para referenciar esses mesmos fenômenos. A série de corredores isotópicos produzidos pelo discurso organizacional compõe o conjunto de significações centrais constitutivas do imaginário social da grande empresa (FREITAS, 1999; 2000). A chave para desvendar essas isotopias é a identificação do mecanismo indutor de significação que converte interesses e necessidades típicos dos negócios - econômicos, sociais, culturais, tecnológicos etc. - em virtudes e qualidades socialmente sancionadas. Essas isotopias caracterizam o modus operandi da empresa contemporânea.

\section{Quadro 1}

\section{Isotopias do imaginário organizacional moderno}

\begin{tabular}{|l|l|}
\hline A empresa cidadã & $\begin{array}{l}\text { O discurso da cidadania empresarial aparece no "apoio à cultura", } \\
\text { "ecologia" e "sustentabilidade". Seu núcleo ideológico opera uma } \\
\text { sobreposição entre interesse econômico e responsabilidade em relação à } \\
\text { sociedade. }\end{array}$ \\
\hline $\begin{array}{l}\text { O lugar da } \\
\text { excelência }\end{array}$ & $\begin{array}{l}\text { O desempenho crescente é exigência-chave e constitui um sistema moral } \\
\text { que engloba toda a conduta do indivíduo, na vida e na empresa. Perseguir } \\
\text { a excelência significa gerir a vida como um projeto, tornar-se um capital } \\
\text { que deve dar retorno. A empresa é o lugar onde o indivíduo pode e deve } \\
\text { almejá-la, para existir e se realizar plenamente. }\end{array}$ \\
\hline $\begin{array}{l}\text { O lugar da } \\
\text { juventude eterna }\end{array}$ & $\begin{array}{l}\text { A palavra de ordem é flexibilidade. A empresa dissimula sua necessidade } \\
\text { de renovação ao apresentar-se como lugar único de realização do } \\
\text { desenvolvimento pessoal: é preciso mobilizar o sujeito de forma total. Ser } \\
\text { flexível é condição de vida; vale qualquer método, receita, guru, } \\
\text { treinamento, prática que prometa pessoas crescentemente maleáveis. }\end{array}$ \\
\hline
\end{tabular}




\begin{tabular}{|l|l|}
\hline $\begin{array}{l}\text { A empresa } \\
\text { restauradora da } \\
\text { ética e da } \\
\text { moralidade }\end{array}$ & $\begin{array}{l}\text { O modelo que consagra apenas o ganhador (os fins justificam os meios) } \\
\text { leva a um mundo de cínicos. O movimento pela ressurreição da ética faz } \\
\text { supor que, sem condições mínimas de confiabilidade, o ambiente se tornou } \\
\text { mortífero. As empresas apresentam-se então como guardiãs de valores } \\
\text { sociais elevados e da moralidade pública. }\end{array}$ \\
\hline $\begin{array}{l}\text { A empresa } \\
\text { comunidade }\end{array}$ & $\begin{array}{l}\text { A empresa se utiliza do discurso da comunidade ou da grande família, } \\
\text { apresentando-se como lugar onde trabalho, convivência e laços fraternos } \\
\text { se juntam de forma entusiasmada e prazerosa, numa experiência a ser } \\
\text { compartilhada por todos os "colaboradores". Os rituais devem ser } \\
\text { cumpridos e vividos com emoção. Tudo em nome da sociabilidade. }\end{array}$ \\
\hline
\end{tabular}

Fonte: adaptado de Freitas (1999; 2000).

A grande empresa é bem equipada para responder às contingências do ambiente; capta mudanças sociais e reage a elas rapidamente. Torna-se uma referência das práticas ordenadoras da realidade e assume o papel de matriz de identidades sociais. Suas isotopias invadem os discursos em disputa na sociedade. As qualidades autodeclaradas - "a organização aparece como grande, potente, nobre, perfeita" (FREITAS, 2000, p. 9) suplementam a frágil identidade dos indivíduos na contemporaneidade, que se veem seduzidos pela imagem magnífica. O discurso organizacional incita a identificação dos sujeitos porque é capaz de captar seus anseios narcísicos por meio da promessa de ser "a fonte de reconhecimento, de amor, de identidade, podendo preenchê-los e curá-los de suas imperfeições e fragilidades" (FREITAS, 2000, p. 9). A empresa alça a condição de instituição à medida que lança mão de seu poderio político-econômico para perseguir o objetivo de universalizar um modo de vida singular e específico. :

[...] as organizações empresariais assumem uma importância que nunca tiveram antes e se oferecem o papel de ator central da sociedade, por meio do qual todas as demais relações devem se organizar. Elas pretendem ser o modelo de racionalidade, de transparência, de produtividade e de resultado que as demais instituições presentes no corpo social devem seguir. (FREITAS, 2000, p. 9)

\section{A Práxis Social do Agir Irrefletido}

As isotopias evidenciam um conjunto de estereótipos e a ideologia da empresa. Como o discurso ideológico é sempre falado para alguém (ALTHUSSER, 1996), apresenta-se a questão pragmática: a eficiência da mensagem dependerá da compreensão e realização dos sujeitos visados como destinatários, neste caso, os indivíduos. A gestão moderna tem o indivíduo como interlocutor privilegiado na estruturação de toda enunciação: Você S/A (a empresa no singular!). O objetivo é capturá-lo oferecendo-lhe um modo de ser.

A marca da empresa capitalista é o controle intenso sobre o trabalho, para elevar a produtividade - equação de tempos relativos: mais-valia relativa - responsável pela produção do excedente. Este é não apenas quantitativo, mas também qualitativo, dado que o exercício de controle assume (novas) formas que visam à subjetividade do trabalhador (FARIA, 2004). Com foco na acumulação infinita, o capitalismo caracteriza-se pela tendência de apropriação ilimitada na relação capital/trabalho. Nas empresas, isso produz a redefinição contínua da relação entre trabalhador e administração. Combinam-se mecanismos de controle para garantir a máxima produtividade e, ao mesmo tempo, elevar o poder de gerência (FARIA, 2004). Essa dinâmica propicia as condições para a ocorrência de uma relação em dois planos: político-ideológico e psicossocial. O capital apropria-se da consciência do trabalhador por meio de mecanismos cada vez mais sutis; e a ciência do 
comportamento, em sua forma de tecnologia de gestão, é intensamente aplicada na elevação da capacidade de trabalho (FARIA, 2004).

O desafio é administrar os indivíduos em sua integralidade e mobilizar a plenitude do ser que trabalha. Para isso, a gestão de pessoas redefiniu e renovou a tradicional função de recursos humanos (DAVEL e VASCONCELLOS, 1995; DAVEL e VERGARA, 2001). A referência à pessoa (ser integral) revela uma ambição: manejar, no campo do real, a simbólica construída pelas isotopias; efetivar os estereótipos e a ideologia, ao fazer funcionar a empresa nos moldes da matriz cultural veiculada. O obstáculo mais evidente é precisamente o confronto com a pessoa, o único recurso organizacional com capacidade de pensamento autônomo e habilidade de refletir a respeito dos atos que pratica.

A gestão de pessoas tem a vocação de operar na base da modelagem linguística do universo (BLIKSTEIN, 1995). Busca apagar a contradição entre discurso e prática, fazendo com que os significados veiculados pela organização coincidam com o [real] vivido pelas pessoas. Dessa intervenção resulta uma "relação fatal de alienação" (BARTHES, 1978). Não é por acaso que pesquisadores da área enfatizam frequentemente a questão, entendendo-a como um paradoxo (LACOMBE e TONELLI, 2001; PEREIRA, CARRIERI e BRITO, 2007; PHILADELPHO e MACÊDO, 2007; VASCONCELOS, MASCARENHAS e VASCONCELOS, 2004).

Esses achados oferecem uma evidência: gestão de pessoas é uma função que se inscreve nesse limite. Operação de risco, dada a ameaça constante de o discurso organizacional esgotar suas possibilidades de coincidir com a realidade representada. Daí a importância da redefinição contínua da relação entre trabalhador e administração; uma estratégia que visa impedir a realidade representada de aparecer sob a forma negativa de uma falha, isto é, de uma não coincidência absoluta entre realidade vivida (prática) e discurso. É o que Zizek (1996) define como curto-circuito do discurso ideológico, lugar em que os signos mostram-se como significantes vazios e a representação formal revela-se contraditória em relação àquilo que pretende corresponder.

A validade desse argumento insinua-se na atual redefinição das práticas oferecidas como solução para as dificuldades inerentes à gestão de pessoas: faz-se apelo direto à experiência, secundando o discurso como meio privilegiado para administrar pessoas. Alguns dos instrumentos em uso nessa nova arquitetura de mobilização subjetiva do empregado são: "treinamento experiencial" (AVANTI CONSULTORES, 2013; CANELA DE EMA, 2013; CONEXÃO AMI, 2013), "treinamento vivencial" (CAPUT CONSULTORIA, 2013) e "treinamento motivacional de alto impacto" (GAUSS, 2009). Todos são apresentados como dinâmicas em que indivíduos ou grupos humanos veem-se submetidos a experiências análogas às do trabalho na empresa. É assim que se justificam atividades tais como construir pontes de bambu e depois caminhar sobre elas, ultrapassar obstáculos naturais numa corda bamba, enfrentar uma corredeira dentro de um bote, avançar mar adentro num caiaque etc.

[O] treinamento de alto impacto [...] Olho de Tigre I ocorre por meio de dinâmicas, nas quais os participantes são estimulados a viver sensações como raiva, tristeza, medo, arrependimento, ansiedade, sofrimento por antecipação [sic] que, correlacionadas à realidade de cada um, são capazes de estimular o participante para atividades em equipe, senso de liderança, trabalho sob pressão, valorização do outro, dentre outras. O Olho de Tigre, realizado há 5 anos, já foi concluído por cerca de 4.000 pessoas. Sem dinâmicas teóricas, tem foco em atividades mentais e duração de 16 horas ininterruptas [...] O Olho de Tigre II segue os moldes do primeiro, mas tem foco específico no desenvolvimento do senso de liderança dos participantes [...] (GAUSS, 2009).

Sensações e reações são estimuladas, enquanto se abdica do tempo da palavra e da reflexão, pois o principal é garantir a fluidez da ação. As pessoas devem ser capazes de adaptação contínua, preparadas para enfrentar processos desconhecidos e problemas nunca vistos; tudo de modo eficaz e econômico. "A questão não é mais a verdade - ainda que aproximativa - do conhecimento, mas seu grau de operacionalidade" (ENRIQUEZ, 
1997b, p. 21). O treinamento experiencial põe às claras a ideologia implícita na ação das corporações: a organização adaptativa é o parâmetro da ação humana e se constrói por meio da formação do indivíduo. É uma inovação que marca a intenção de fazer convergir práxis social e interesses corporativos. Na educação de executivos, a instrumentalização da experiência ganha claros contornos pedagógicos. Há iniciativas como o Global Management Program - promovido pela Universidade Quantum, que oferece cursos de formação continuada com uma visão holística - em que um grupo de executivos viaja duas semanas por Bali, na Indonésia:

[...] parte do dia é dedicada às aulas em um ambiente mais formal, outro período é voltado para atividades turísticas, culturais ou de reflexão pessoal... A programação incluiu também visitas a um parque de elefantes e a um vulcão. "Todos os momentos são repletos de aprendizado", afirma Claudia Riecken, presidente do grupo Quantum. "Observar uma sociedade tão única ensina sobre aspectos como gestão da mudança, diversidade e resistência à pressão". (SOARES, 2011)

O treinamento experiencial é também utilizado em programas de MBA Executivo da Universidade do Tennessee, como relata Judge (2005). Aqui a objetividade é garantida pelo apelo a uma escala com "as cinco melhores práticas em liderança" [sic], reproduzidas no Quadro 2. Dois especialistas observam o esforço da equipe e categorizam os comportamentos de acordo com a gradação. Três atividades compõem o treinamento: (a) galgar uma parede de 10 metros e descer por uma corda; (b) construir uma ponte sobre o leito de um pequeno rio; (c) seguir, em grupos, por uma trilha num bosque, amarrados uns aos outros.

Durante as atividades, além de atentar para os requisitos de liderança, os grupos devem encontrar peças de um foguete para ser montado no final. Para acirrar a competição, um placar mostra o desempenho das equipes ao longo do dia.

\section{Quadro 2}

\section{As cinco melhores práticas de liderança de Kouzes \& Posner}

\begin{tabular}{|l|l|}
\hline \multirow{2}{*}{ 1. Desafiar o processo } & Procurar oportunidades desafiadoras para mudar, crescer, inovar e melhorar; \\
\cline { 2 - 2 } & Experimentar, assumir riscos a aprender com os erros; \\
\hline \multirow{2}{*}{$\begin{array}{l}\text { Compartilhada } \\
\text { 3. Capacitar os outros a a } \\
\text { agir }\end{array}$} & $\begin{array}{l}\text { Visão positiva do futuro } \\
\text { esperanças e sonhos } \\
\text { confiança }\end{array}$ \\
\cline { 2 - 3 } & $\begin{array}{l}\text { Empoderar as pessoas, cedendo poder, oferecendo escolhas, desenvolvendo } \\
\text { competências, designando tarefas críticas e oferecendo apoio }\end{array}$ \\
\hline \multirow{2}{*}{ 4. Modelar o caminho } & Dar exemplo, comportando-se coerentemente com os valores compartilhados \\
\cline { 2 - 3 } & Alcançar pequenas vitórias que promovem progresso consistente e compromisso \\
\hline \multirow{2}{*}{ 5. Encorajar o coração } & Reconhecer contribuições individuais para o sucesso de cada projeto \\
\cline { 2 - 2 } & Celebrar regularmente as conquistas da equipe \\
\hline
\end{tabular}

Fonte: (JUDGE, 2005, p. 291) 
Para controlar os resultados, os participantes são levados a medir suas habilidades de liderança, antes e depois, sempre com base no modelo. Também é feita uma pesquisa de opinião para captar a percepção sobre o benefício do treinamento. Ainda assim, a confiabilidade dos procedimentos não é garantida:

[...] a aprendizagem baseada em aventura tem um enorme potencial, mas porque não há muitos modelos para essa abordagem, temos de experimentar e partilhar as nossas experiências sobre as lições aprendidas. Se o objetivo é mais do que apenas conhecimento conceitual para suas iniciativas de desenvolvimento de liderança [...] Ainda que seja útil uma visita à literatura experimental, recomendamos que você simplesmente "faça... e tente entender". (JUDGE, 2005, p. 299)

Esse impulso para a ação marca o instrumental de treinamento experiencial. É precisamente esse o aspecto essencial, pois ao operar o limite da ideologia posta no discurso organizacional, a função gestão de pessoas encontra o ponto em que a compreensão deve ser paralisada, sob pena de esgarçar a ordem discursiva fabricada. Isso faz retornar o "recurso" humano no lugar da "pessoa" humana, fechando a organização ao pensamento autônomo e à reflexão questionadora. A analogia com a crítica à tradição da linguística moderna (BLIKSTEIN, 1995) é esclarecedora: ao aceitar a linguagem como molde do pensamento, a gestão de pessoas se obriga a abdicar da práxis social, para promovê-la como falsificação. Toda a experiência individual deve ser reconvertida nos termos das habilidades necessárias à empresa. O uso indiscriminado de escalas para categorizar os comportamentos é um dos sintomas dessa incessante instrumentalização da subjetividade. O conteúdo propriamente humano, responsável pelo engendramento mesmo da linguagem (significação e sentido) acaba reprimido.

Como a gestão de pessoas está fadada a fracassar em seu intento, percebe-se aí o paradoxo antes referido (VASCONCELOS, MASCARENHAS e VASCONCELOS, 2004). A fragilidade implícita à sujeição completa reside na virtual impossibilidade de extinguir do desejo humano a originalidade e a autonomia: a noção mesma de pessoa pressupõe certo grau de anormalidade, alguém capaz de se interrogar e de se lançar no desconhecido (ENRIQUEZ, 1997b). Se integrarem unicamente sujeitos heterônomos, as empresas acabarão por reforçar seus vínculos com sujeitos autônomos: é nas pessoas e não nos recursos humanos que reside o essencial - pensamento, reflexão, criatividade e inovação - sem o que a empresa se torna autofágica. $\mathrm{O}$ esforço em integrar os sujeitos - oferecer-lhes uma pretensa humanidade com sensações, experiências e simulações de pessoas passíveis de serem geridas - encontra muito mais que a fronteira do discurso. O limite real está nas próprias pessoas de carne e osso, que não têm outra saída senão resistir. Coloca-se então: o que a gestão de pessoas enfrenta? Qual é seu antagonista?

A resposta é elaborada aqui de maneira pouco usual. Opta-se por uma narrativa sobre o quanto uma pessoa é capaz de subverter a ordem. Se a completa sujeição conduz ao extermínio do humano na organização, sua plenitude deixa antever outros limites. Tudo indica que a operação e o problema da gestão de pessoas residem na necessidade de produzir simultaneamente a completa sujeição e o sujeito pleno.

\section{Beleza Americana: a Pessoa Insuportável à Ordem da Organização...}

A ficção "fornece um método alternativo de pensar e falar a respeito de organizações que revela aspectos inusitados e interessantes do fenômeno organizacional" (PHILIPS, 1995, p. 634). O filme cria um espaço para a representação do mundo, na qual os indivíduos se encontram a si mesmos. A realidade pode se manifestar com intensidade na narrativa ficcional, o que complementa a análise organizacional ao oferecer um modo de unir o "não-lógico, não-racional e puramente experiencial da organização com modelos de análise teóricos": a combinação da narrativa fílmica com a análise tradicional "promove uma nova arena intertextual, na qual as teorias 'ganham vida'”(PHILIPS, 1995, p. 635). 


\section{...olhe de mais perto}

Beleza americana é a história de uma família. O conflito com as regras sociais está no centro de um drama que apresenta os signos da decadência das instituições: "[...] dos valores tradicionais da família, da escola, da nação, da pátria e, sobretudo, da paternidade, do pai, da lei do pai e da autoridade sob todas as formas" (ROUDINESCO, 2002, p. 10).

O publicitário quarentão Lester Burnham é um pai de família com um bom emprego, esposa fiel e uma filha adolescente típica; ou pelo menos tentava acreditar nisso. Quando essa crença começa a desmoronar, decide mudar de vida: abandona o emprego, muda os hábitos, confronta as virtudes do homem comum. A mudança desencadeia grande insegurança na esposa Carolyn e em Jane, sua filha. O comportamento de Lester vai, progressivamente, ameaçando os vizinhos e todos aqueles que o cercam, até alcançar um trágico desfecho. Já no prólogo, o final é anunciado quando a adolescente confessa seu desejo e suas razões: ela classifica o pai como entediante e socialmente desastrado.

A esposa é corretora de imóveis. Não tem a menor ideia do problema do marido, nem do seu. Ela não é diferente de milhares de pessoas que, ao sentirem o vazio em suas vidas, tentam preenchê-lo adquirindo as coisas "certas": a posse desses itens acerta sua vida. Ela exibe um comportamento padrão e reitera a centralidade da família, os valores competitivos nos estudos, no trabalho e, sobretudo, a alegria do conformismo. É obcecada por transmitir uma imagem positiva que lhe traga o respeito na comunidade: ter o carro certo, um jardim bonito, vestir as roupas certas, que lhe dão a sensação de segurança e bem-estar e a resguardam numa identidade. Querer agradar um grande número de pessoas a induz a uma resignação absoluta, regra áurea e condição sine qua non do sucesso e do reconhecimento público.

Quando Lester começa a mudar, Carolyn se vê forçada a isso. Consciente ou inconscientemente, percebe algo errado. Ouve fitas motivacionais, lê livros de autoajuda ("Our money, Our life" é o título do livro em seu carro, "um best-seller nacional") e repete constantemente frases de afirmação de sucesso pessoal, na esperança de manter o controle.

Ao comentar a modernidade em Baudelaire, Walter Benjamin escreve:

O herói é o verdadeiro tema da modernidade. Isto significa que para viver a modernidade é preciso uma formação heroica. [...] Os obstáculos que a modernidade opõe ao élan produtivo natural do indivíduo encontram-se em desproporção com as forças dele. É compreensível que o indivíduo fraqueje, procurando a sorte. A modernidade deve estar sob o signo do suicídio que sela uma vantagem heroica que nada concede à atitude que lhe é hostil. Este suicídio não é renúncia, mas paixão heroica. [...] Ele está destinado à derrota e não precisa ressuscitar qualquer dos trágicos para apresentar tal necessidade. (BENJAMIN, 1975, p. 12-16)

Lester comete um suicídio profissional ao afrontar o chefe, as normas e as condutas organizacionais em vigor. Esse é o primeiro traço de sua empreitada. Para que possa existir o "novo Lester", o "velho" deve sucumbir. É a recusa a uma existência que ele julga insatisfatória, intolerável. O renascimento metafórico lhe outorga a habilidade de responder a agressões sociais, pois adquire voz ativa e liberdade, na solidão e no abandono.

A resignação que caracteriza Carolyn é antagônica a Lester. O suicídio profissional tem ampla carga simbólica, pois é o modo de tornar-se protagonista de si mesmo, superar a vida nua (AGAMBEN, 2002). Como num rito de passagem, ele abandona a condição de vivente submisso - ao chefe, à organização, à vida como ela é. A ligação do suicídio com o rito de passagem permite alcançar múltiplos sentidos na sua ação, cujo impacto na trama advém da representação social de uma ação radical, sem razão ou medida, que parece 
escapar ao sentido. As atitudes de Lester não fazem parte da cartilha social moderna. Seu suicídio metafórico é decisão de uma pessoa e sua performance está fundada na pretensão singular.

O conflito com as regras sociais está no centro do drama. Seria possível viver uma vida que fosse nada mais que um espelho social de reconhecimento e aceitação? Parece que não. Enquanto outros são preservados e se protegem nos segredos, Lester é executado por corporificar a lei e a transgressão. Ele ultrapassa conscientemente as proibições e choca-se com a ordem. Está consciente disso. Em sua sombria desmedida (hýbris), tende a se tornar um herói paradoxal, sem as qualidades excepcionais disponíveis nos super-homens de massa. Aos olhos de vários que o cercam, ele é um fracassado (looser).

O velho Lester vivia o tédio, a depressão, a perda do sabor, do sentido, dos pontos de referência ordinários que ligam o homem à vida. Mas, é um homem com o desejo exacerbado, que quer analisar seus dados para sacudi-los e recolocá-los em questão. Ele renasce como indivíduo que valoriza o desejo inaugural e sempre renovado do sujeito, de inventar, ousar e gozar, a despeito das angústias, desesperos, erros e até mesmo dos crimes, em um esforço incessante, a fim de levar uma vida ainda mais ampla e intensa. Marca uma passagem dos limites. Para ele, romper regras torna-se uma eventualidade que não pode ser evitada. Ele se torna extravagante, "[...] um ser que, de um lado, sai dos caminhos ordinários [...] que sai dos limites do senso comum ou do que é considerado regra ou norma. Em suma, um ser a uma só vez extraordinário e insensato [... que] se definiria por três características: uma audácia que se avizinha da loucura; o pathos da novidade; o amoralismo além do bem e do mal" (ABENSOUR, 2006, p. 205).

Lester é uma pessoa, um indivíduo "de facto" (BAUMAN, 2001, p. 48), porque adquiriu controle sobre seu destino e toma as decisões que em verdade deseja. Não foi destituído do seu lugar de direito e conduzido ao espaço de exceção. Ele optou por isso, escolha suficiente para ser considerado estranho pelos que o rodeiam - "Não perdi [o emprego]. Sei onde ele está. Eu é que caí fora!". Ele evidencia a resiliência: "capacidade em conseguir viver e se desenvolver positivamente, de maneira socialmente aceitável, a despeito do estresse ou de uma diversidade que comporta normalmente o grave risco de um resultado negativo" (CYRULNIK, 1999, p. 10). O conceito revela dois focos: de um lado a eficiência, o controle, a constância e a previsibilidade; de outro, a persistência, a adaptabilidade, a variabilidade e a imprevisibilidade. "Vista do exterior, a frequência da resiliência prova que se pode escapar. Vista do interior, é estruturada como um oximoro que revela a divisão interior de um homem ferido, a coabitação do céu e do inferno, a felicidade sobre o fio da navalha" (CYRULNIK, 1999, p. 16).

É o encontro com o oximoro que permite compreender a vivência de Lester: é a figura de retórica que associa dois termos antinômicos e faz aparecer o contraste daquele que, ao receber um grande golpe, adaptase ao se clivar. Estranho às regras de convivência estamentárias, mas resiliente: as atitudes de Lester são vistas como insultuosas, tornando-o um transgressor. Faz coisas que não deveria fazer, seu comportamento é percebido como funesto, seus gestos são mal interpretados (GIRARD, 2004). A recusa ao sucesso profissional a qualquer preço é escandalosa: o vizinho o considera um homossexual enrustido; a filha o classifica como pervertido; para o ex-chefe é um doente; e, para a esposa, uma péssima referência para a filha adolescente. Creem ter enlouquecido, é um mau exemplo para a comunidade inteira. $\mathrm{O}$ escândalo fortalece a coesão entre os escandalizados. O estranho, segundo Bauman (2001), handicapped (portadores de vantagem ou desvantagem) para Girard (2004), é objeto de medidas propriamente discriminatórias e vitimárias: "No monstro mitológico, o 'físico' e o 'moral' são inseparáveis [...]. Em numerosos mitos, basta a presença do desgraçado na vizinhança para contaminar tudo o que o cerca" (GIRARD, 2004, p. 45-51).

Bode expiatório é aquele que leva a mensagem, que é enviado em missão. É a pessoa sobre quem se faz recair as culpas alheias ou a quem são imputados todos os reveses. Entre os perseguidores há a crença "na culpabilidade de sua vítima, seu aprisionamento na ilusão persecutória" compondo um "verdadeiro sistema de representação." (GIRARD, 2004, p. 57). "Às causas naturais, longínquas e inacessíveis, a humanidade sempre preferiu as causas significativas sob o aspecto social e que admitem uma intervenção corretiva, em outras palavras, as vítimas" (GIRARD, 2004, p. 263-264). Tenta-se fazer das pessoas estranhas bodes expiatórios, em meio aos ódios e desejos de todos. Lester morre porque enuncia o desejo de outros, que não 
querem ouvi-lo; ninguém mais quer ouvir. A verdade proferida por ele é causa suficiente para o homicídio, sinal de seleção vitimária. Ele conhece os segredos, esse fio condutor que diz da vida privada de todos.

A palavra segredo (do latim secretus, particípio passado do verbo irregular secerno) é composta pelo verbo cerno, peneirar e pelo prefixo se, indicando a separação. Daí derivam discerno, discernir, excerno, excremento e secerno, secreção, segredo, secreto. Definido como um saber oculto a outrem, o segredo envolve três temas principais: o saber, a dissimulação desse saber e a relação com o outro que se organiza a partir dessa dissimulação. Seu conteúdo deve ser guardado, pois a evocação de um fenômeno de secreção é a traição, a violação do segredo. É incômodo para quem está excluído dele e pode ser insuportável para quem o detém. "A ordem social funda-se sobre a simbolização e a repressão. Não existe ordem sem palavras proibidas e sem palavras de referência, sem tabus e sem domínios permitidos" (ENRIQUEZ, 1990, p. 184). O segredo é um dos fundamentos da estabilidade social. Ele confere poder. Se tudo fosse conhecido, essa forma/força discreta de manutenção da ordem, que consiste na resignação, explodiria em pedaços. $\mathrm{O}$ medo desempenha seu papel na preservação do segredo. Fosse Lester um trisckster [trapalhão], sua sobrevivência estaria garantida e seu caráter, consagrado. Cabe lembrar que o trickster é um personagem que, ao tentar imitar de forma ridícula e imbecil os gestos do criador, desencadeia consequências catastróficas e cômicas, com o dom de confundir as coisas. Esse tipo de personagem aparece de maneira livre, frequentemente louca, inesperada para provocar incidentes e deles zombar com impunidade. Trata-se de um "convertedor da desordem" institucionalizado (ENRIQUEZ, 1990, p. 232), um elemento habitual do sistema social, que não está a serviço de nenhum poderoso; o que não é o caso de Lester.

Lester mostra a fraqueza que constitui o homem, as fragilidades acentuadas pelo cumprimento do padrão de sucesso, de respeito, de reconhecimento, a falta de sentido nas ações. Pelo que estão combatendo? Eles não sabem responder. Ele revela a essência de vidro, prestes a se quebrar. Lester possui a marca distintiva do exílio autoimposto: "a recusa a ser integrado; a determinação de situar-se fora do espaço, de construir um lugar próprio, diferente do lugar em que os outros à volta se inserem, um lugar diferente dos lugares abandonados e diferente do lugar em que se está" (BAUMAN, 2001, p. 238).

A recusa em mover-se e o segredo revelado impõem uma pena ao traidor. O castigo que deriva do dano causado à sociedade, do perigo que representa. Não pode ser apenas proscrito, permanecer no limbo. Deve ser eliminado, pois "[o] bode expiatório designa simultaneamente a inocência das vítimas, a polarização coletiva que se efetua contra elas e a finalidade coletiva dessa polarização. Os perseguidores se fecham na 'lógica' da representação persecutória e não podem mais dela sair" (GIRARD, 2004, p. 55). O sacrifício consiste em descarregar sobre o bode expiatório os ódios e tensões acumulados, que ameaçavam romper a unidade social e surgem, para os participantes, da impossibilidade de conciliar os desejos humanos. $\mathrm{O}$ ato encerra em si um momento negativo: "ele significa uma limitação do desejo sensível, uma renúncia a que se impõe o eu [...] Em contrapartida, já se nos revela, nos primeiros estágios do sacrifício, uma outra direção do querer e fazer humanos. Pois a força do sacrifício se fundamenta na renúncia que contém". Pode assumir diferentes formas: oferenda, purificação, agradecimento ou expiação: "em todas essas formas, ele sempre constitui um núcleo rígido, em torno do qual a ação do culto se reúne. Aqui a 'fé' religiosa alcança sua verdadeira visibilidade, aqui ela se transforma imediatamente em fato" (CASSIRER, 2004, p. 370-373).

Que fé se torna visível no altar do sacrifício de Lester? O que reificam os que participam, em ato ou em vontade, de sua execução? Demonizam o feio, o impuro, o caos, o atraso, o fracasso, a fragilidade. Glorificam aquilo que consideram beleza, limpeza, ordem, progresso, sucesso e virtude. Após a cerimônia expiatória, continuarão a avançar com as cabeças e os ombros curvados sob o peso de suas certezas, eliminando as vivas ervas daninhas, exterminando os estranhos e os transgressores que surgem ou se esgueiram pelas brechas. Renovam sua crença nos cânones de uma sociedade plástica que produz e cultiva "Belezas americanas [American beauty]": rosas vistosas e robustas, sem cheiro, nem espinhos. 


\section{Heróis e Anti-heróis: a Perspectiva da Gestão de Pessoas}

Ao pensar a organização como cultura, Prestes Motta (1995b, p. 22) enfatiza a precariedade de sua ordem. "[O]s desviantes [...] têm o potencial tanto de serem criativos quanto destrutivos, heróis e anti-heróis são igualmente carismáticos, poderosos e misteriosos, e, com muita frequência, difíceis de distinguir". Herói e anti-herói podem transformar-se um no outro, tanto mais quanto mais "poderoso, carismático e 'mágico' o herói". Lester é uma pessoa de grande valor simbólico, precisamente, porque se define pelo dúbio. Ele incorpora o antagonismo que produz um curto-circuito nos pressupostos da gestão de pessoas: não se pode ser plenamente "adaptativo", "criativo" e "proativo", sob pena de fazer ruir a ordem da organização.

A gestão de pessoas funciona como os aparelhos ideológicos de Estado (ALTHUSSER, 1996). Em ambos os casos, a ideologia tem forma social específica num poder organizado e instituído; os aparelhos determinamse mais pelo seu funcionamento como prática do que pelo seu valor jurídico formal. A ideologia não é discurso falso ou vazio resultante da imaginação humana, "manifesta-se num aparelho que [...] prescreve práticas materiais reguladas por um ritual material; práticas que existem nos atos materiais de um sujeito". Conforme Althusser, as ideias aparecem e desaparecem "inscritas nos atos das práticas reguladas por rituais definidos em última instância por um aparelho ideológico" (apud VAISMAN, 2006, p. 16).

O mundo plasmado pela gestão de pessoas padroniza a subjetividade: deseja produzir respostas afetivas por meio de um controle abrangente dos indivíduos. A adoção dos novos métodos de treinamento experiencial objetivam produzir "a adesão, o envolvimento, a mobilização total de todos; quer dizer, uma psique sem conflitos, a serviço da organização" (ENRIQUEZ, 2001, p. 50), que fica impossibilitada de enfrentar a complexidade e demonstrar capacidades criativas imprevistas e não-programáveis. Forçar a experiência é um modo de submeter o sujeito a pressões que o desestabilizam e o fazem interiorizar as respostas solicitadas. A intenção de administrar a subjetividade mobiliza crescentemente as empresas. Embora sejam capazes de reconhecer a psique como força operante, essas inovações resultam em sua "destruição ou, ao menos, sua sujeição sempre no consentimento e no contentamento dela própria" (ENRIQUEZ, 2001, p. 78), com resultados diversos dos pretendidos inicialmente.

A retração do discurso em favor da sensação e da experiência é um importante sintoma da contemporaneidade. A novidade surge, portanto, ao se extirpar do lugar de trabalho a experimentação que ousa e transforma, porque é para afirmar o seu contrário que a experiência tem sido evocada. Paralisa o sujeito incitando-o à ação irrefletida. Na gestão de pessoas, a mudança de nome sedimenta definitivamente a visão de pessoas como recursos. Dessa perspectiva revela-se o equívoco em pensar uma possível coincidência entre discurso e prática em gestão de pessoas. É exatamente a distância entre ambos que alimenta as inovações nessa especialidade. Tendências recentes indicam o descarte do problema dessa relação: vai-se direto à ação! É assim que sob a alegação de simular vivências e desafios do trabalho, um grupo de vendedores de uma empresa qualquer, no auge de sua forma física, é convidado a se aventurar numa corredeira. Alguns não sabem sequer nadar.

Lester Burnham ilustra os limites da ordem/subversão e com isso traz à luz o grande fantasma da gestão de pessoas: aquele que ela precisa reprimir. Se gerir pessoas é também controlá-las, no limite está a sujeição completa: a mortificação do sujeito. Assim, chegamos à superação do paradoxo, pois parece não haver como promover o almejado encontro entre sujeito sujeitado e sujeito pleno, se para tanto é preciso que este morra, ao menos, simbolicamente.

\section{Considerações Finais}

A gestão de pessoas apresenta-se num discurso oficial que induz expectativas irrealizáveis, frustração, estresse. Os ideais de qualificação e aprendizagem parecem desconectados do trabalho cotidiano. Essas contradições são apresentadas na literatura como um paradoxo. Este artigo propôs ir além, ao mostrar que a não coincidência entre discurso e prática é um mecanismo central à produção de sentidos por parte das 
empresas. O trabalho ideológico na base desse esforço é a conversão das necessidades dos negócios em virtudes e qualidades sociais: devemos todos ser sujeitos de nossa própria sujeição. A acumulação infinita está intimamente ligada à redefinição contínua da relação entre trabalhador e administração. A gestão de pessoas é função que responde por essa operação, redefinindo continuamente essa relação, numa estratégia que visa impedir que a realidade enunciada se apresente no negativo. A garantia da coincidência entre a prática e o discurso deve ser alcançada pela insistente reiteração e reinvenção de símbolos. Se numa primeira aproximação vê-se um paradoxo, quando se olha mais de perto, entende-se que a contradição tem a forma do segredo, escancarado por Lester Burnham. Aquilo que enraíza a ordem da organização não se deve enunciar. Esse discurso é e será sempre dissimulado: ele é, essencialmente, o não dito.

Pessoas devem se adaptar continuamente aos processos e problemas de modo eficaz e econômico. A isso se chama aprendizagem. As novas técnicas de treinamento atualizam a ideologia das corporações. As mudanças de nome - de que a "gestão de pessoas" é ela mesma uma expressão - revelam por si o necessário deslizamento linguístico correlato à flexibilidade. $\mathrm{O}$ objetivo da aprendizagem é o ajustar incessante às necessidades da empresa: é o sujeito-gelatina.

As estratégias para realizá-lo variam, mas todas no mesmo diapasão: “faça... e tente entender" (JUDGE, 2005 , p. 299). São estimuladas sensações e reações com a abdicação da palavra. Os indivíduos são empurrados para a ação sem reflexão, aquém e além da explicação, do entendimento, do próprio discurso. Se da perspectiva empresarial, tudo isso parece adequado, ao destituir a vontade própria do sujeito, esta lhe provoca uma inclinação a partir da qual nada é edificado. $O$ resultado é a produção de um sujeito no negativo. Do discurso negativo ao sujeito negativo: tudo em nome da gestão de pessoas.

\section{Referências}

ABENSOUR, M. O heroísmo e o enigma revolucionário. In: NOVAES, Adauto (Org.). Tempo e História. São Paulo: Companhia das Letras, 2006.

AGAMBEN, G. Homo sacer: o poder soberano e a vida nua. Belo Horizonte: Ed. UFMG, 2002.

ALTHUSSER, L. Ideologia e aparelhos ideológicos de Estado. In: ZIZEK, S. (Org.). Um mapa da ideologia. Rio de Janeiro: Contraponto, 1996.

AVANTI CONSULTORES. Projeto Ponte. Disponível em: <http://www.youtube.com/watch?v=bJ1ykIfNffM>. Acesso em: 13 nov. 2013.

BARTHES, R. Aula. São Paulo: Cultrix, 1978.

BAUMAN, Z. Modernidade líquida. Rio de Janeiro: Jorge Zahar Editores, 2001.

BELEZA Americana...olhe bem de perto. Título original: American Beauty... look closer. Direção: Sam Mendes. Site: oficial: www.americanbeauty-thefilmBENJAMIN, W. A modernidade e os modernos. Rio de Janeiro: Tempo Brasileiro, 1975. (Biblioteca tempo universitário, 41).

BLIKSTEIN, I. Kaspar Hauser ou a fabricação da realidade. São Paulo: Cultrix, 1995.

BURKE, V.; COLLINS, D. Optimising skills transfer via outdoor management development: Part I: the provider's perspective. Journal of Management Development, v. 23, n. 7, p. 678-696, 2004.

CANELA DE EMA Ecotreinamento. Outdoor training. Disponível em: <http://www.youtube.com/watch?v=7t9X7u5mCbo>. Acesso em: 13 nov. 2013. 
CAPUT CONSULTORIA. Treinamento vivencial: arvorismo. Disponível em: <http://www.youtube.com/watch?v=5Jws3zfTGZE>. Acesso em: 13 nov. 2013.

CASSIRER, E. A filosofia das formas simbólicas: o pensamento mítico. São Paulo: Martins Fontes, 2004.

CONEXÃO AMI. Treinamento vivencial de alto impacto. Disponível em: <http://www.youtube.com/watch?v=IEepHMQD2kY>. Acesso em: 13 nov. 2013.

CYRULNIK, B. Um merveilleux malheur. Paris: Editions Odile Jacob, 1999.

DAVEL, E.; VASCONCELLOS, J. (Org.). “Recursos” humanos e subjetividade. Petrópolis: Vozes, 1995. ; VERGARA, S. (Org.). Gestão com pessoas e subjetividade. São Paulo: Atlas, 2001.

ENRIQUEZ, E. Da horda ao Estado: psicanálise do vínculo social. Rio de Janeiro: Jorge Zahar Editores, 1990.

. A organização em análise. Rio de Janeiro: Vozes, 1997a.

. O indivíduo preso na armadilha da estrutura estratégica. Revista de Administração de Empresas, São Paulo, v. 37, n. 1, p. 18-29, jan./mar. 1997 b.

. A interioridade está acabando? In: MACHADO, M. N. M. et al. Psicossociologia: análise social e intervenção. Belo Horizonte: Autêntica, 2001.

FARIA, J. H. Economia política do poder. Curitiba: Juruá, 2004. v. 1.

FREITAS, M. E. Cultura organizacional: identidade, sedução e carisma? Rio de Janeiro: FGV, 1999.

. Contexto social e imaginário organizacional moderno. Revista de Administração de Empresas, São Paulo, v. 40, n. 2, p. 6-15, abr./jun. 2000.

GAUSS Consulting. Treinamento motivacional de alto impacto (material de divulgação). Disponível em: < http://www.gaussconsulting.com.br/si/site/11010300>. Acesso 29 jul. 2009.

GIRARD, R. O bode expiatório. São Paulo: Paulus, 2004.

GRANT, D.; KEENOY, T.; OSWICK, C. Organizational discourse. International Studies of Management and Organization, London, v. 31, n. 3, p. 5-24, 2001.

JUDGE, W. Adventures in creating an outdoor leadership challenge course for an EMBA Program. Journal of Management Education, v. 29, n. 2, p. 284-300, 2005.

KILIMNIK, Z. M.; REIS, E. M. O treinamento experiencial e sua aplicação no contexto corporativo. Revista da FAE, Curitiba, v. 13, n. 2, p. 17-30, jul./dez. 2010.

LACOMBE, B. M.; TONELLI, M. J. O discurso e a prática: o que nos dizem os especialistas e o que nos mostram as práticas das empresas sobre os modelos de gestão de recursos humanos. Revista de Administração Contemporânea, Curitiba, v. 15, n. 2, p. 157-174, maio/ago. 2001.

META TREINAMENTO CORPORATIVO. Disponível em: <http://www.metatreina.com.br>. Acesso em: 15 jul. 2013.

PEREIRA, M. C.; CARRIERI, A. de P.; BRITO, J. de B. Práticas de gestão e relações de poder no espaço organizacional: representação social de trabalhadores em uma multinacional. In: ENCONTRO DE GESTÃO DE PESSOAS E RELAÇÕES DE TRABALHO, 1., 2007, Natal. Anais... Natal: ANPAD, 2007. 1 CD-ROM.

PHILADELPHO, P. B. G.; MACEDO, K. B. Avaliação de desempenho como um instrumento de poder na gestão de pessoas. Aletheia, n. 26, p. 27-40, dez. 2007. 
PHILIPS, N. Telling organizational tales: the role of narrative fiction in the study of organizations. Organization Studies, London, v. 16, n. 4, p. 625-649, 1995.

PRADO, M. Caveira motivacional. Revista da Folha, São Paulo, 23 mar. 2008. Disponível em: <http://www1.folha.uol.com.br/revista/rf2303200816.htm>._Acesso em: 21 jun. 2013.

PRESTES MOTTA, F. C. Cultura nacional e cultura organizacional. In: DAVEL, E.; VASCONCELLOS, J. (Org.). "Recursos" humanos e subjetividade. Petrópolis: Vozes, 1995a.

. Cultura nacional e cultura organizacional. Revista da ESPM, v. 2, n. 2, p. 17-23, ago. 1995b.

REIS, E. M. O treinamento experiencial e sua aplicação no contexto corporativo: estudo comparativo entre programas realizados nos Estados Unidos e no Brasil. 2010, 102f. Dissertação (Mestrado em Administração de Empresas) Faculdade de Ciências Empresariais, Universidade FUMEC, Belo Horizonte, 2010.

ROUDINESCO, E. La famille en désordre. Paris: Librairie Arthème Fayard, 2002.

SOARES, V. Reciclagem mental. Valor Econômico, São Paulo, 10 out. 2011. Valor Investe. Disponível em: <http://www.valor.com.br/carreira/1043832/reciclagem-mental>._Acesso em: 10 out. 2011.

VAISMAN, E. Althusser: ideologia e aparelhos de Estado - velhas e novas questões. Projeto História, São Paulo, n. 33, p. 247-269, dez. 2006.

VASCONCELOS, I. A dialética da mudança: uma análise crítica do conceito de paradoxos organizacionais. NPP/EAESP/FGV Relatório de Pesquisa 6/2004. São Paulo, 2004. Disponível em: <http://bibliotecadigital.fgv.br/dspace/handle/10438/3120>. Acesso em: 13 nov. 2013.

; MASCARENHAS, A. O.; VASCONCELOS, F. C. de. Paradoxos organizacionais, Gestão de pessoas e tecnologia na Souza Cruz. RAE-eletrônica, v. 3, n. 2, p. 1-20, jul./dez. 2004

ZIZEK, S. (org.). Um mapa da ideologia. Rio de Janeiro: Contraponto, 1996. 